\title{
LA MEDIACIÓN FAMILIAR Y EL DERECHO DE NIÑAS, NIÑOS Y ADOLESCENTES A SER ESCUCHADOS
}

\section{CHILDREN AND TEENAGERS RIGHTS IN FAMILY MEDIATION}

\section{Resumen \\ $\mathrm{E}$} $n$ el presente artículo se valora si la mediación en general, y la participación de niñas, niños y adolescentes en sus procesos, constituyen una herramienta para garantizar los derechos de las personas menores de dieciocho años instituidos en la Convención sobre los Derechos del Niño y la Ley General de los Derechos de Niñas, Niños y Adolescentes. En particular se analiza el derecho a tener una opinión propia, a ser escuchados y a participar en las decisiones sobre asuntos que les afectan. Aunque forma parte de una investigación más amplia, que incluye la sistematización y evaluación de procesos de mediación, en este documento se incluye únicamente información derivada de la revisión documental. Ello representa una limitación, sin embargo, aporta elementos para la reflexión y discusión sobre la mediación y la participación de niñas, niños y adolescentes en sus procesos, como herramienta para favorecer el cumplimiento y garantía de derechos. Se concluye que la mediación representa un mecanismo para el acceso a la justicia, tanto para las personas adultas como para las menores de edad. Que involucrar a los niños y adolescentes les constituye como sujetos, les abre la posibilidad de ser escuchados, expresar sus opiniones en un ambiente en que son validadas y les invita a tomar parte en las decisiones que les afectan y asumir responsabilidad sobre ello.

Palabras clave: mediación familiar; derechos de la infancia; conflicto; relación dialógica, comunicación asertiva.

\section{Abstract}

7 his article seeks to evaluate whether mediation in general, and with the participation of children and teenagers in its processes as a tool to guarantee the rights of underage population as declared in the Convention on the Rights of the Child and the The General Law on the Rights of Children and Adolescents. In particular the right to have their own opinion, to be heard and to participate in decisions about matters that affect them. Although it makes part of a wider investigation which encompasses the evaluation and systematization of mediation processes, this document comprises exclusively information sourced in documentation. This is a limitation. However, it makes for a good starting point for reflection and discussion

1 Profesora investigadora de tiempo completo de la Universidad Autónoma de Ciudad Juárez, México. Correo electrónico: maria.almada@uacj.mx; ORCID: 0000-0002-2154-0458. 
about mediation and the participation of children and teenagers in its processes as a tool to encourage the fulfillment of their rights. It will be concluded that mediation represents a viable device to access justice for people of all ages, adults or underage, and that involving children and teenagers reinforces them as individuals, opens the possibility of being heard and express their opinions in a safe environment while inviting them to take part in the decision making that affects them directly, and take responsibility of it.

Key words: family mediation, underage rights, conflict, dialogic relationships, assertive communication.

\section{Introducción}

La Convención sobre los Derechos del Niño (ONU, 1990) reconoce a las personas menores de dieciocho años como titulares de derechos y establece, entre otros, los derechos a la participación, a tener una opinión propia y expresarla, a ser escuchadas y a que sus opiniones sean tomadas en cuenta. Ante el estatus de ordenamiento jurídico, los Estados se comprometen a hacer lo necesario para promover y garantizar estos y todos los derechos incluidos en la Convención. En México, tales derechos se han consagrado en la Ley General de los Derechos de Niñas, Niños y Adolescentes, aprobada en 2014.

El reto de hacer vida la Convención es de gran envergadura, pues implica un cambio cultural profundo, que lleve a los adultos a reconocer y validar a niñas, niños y adolescentes como interlocutores válidos, con experiencias, opiniones y sentimientos diferentes y únicos, capaces de tomar decisiones y de asumir responsabilidades, entre otras cosas. Esto exige una transformación en las relaciones de poder y en la forma, en general, como el mundo adulto se ha relacionado con los más pequeños en una relación vertical y autoritaria, en la que uno manda y el otro obedece, uno controla y el otro es so- 
metido; una relación que da pie y justifica la violencia como forma de "resolver" los conflictos.

Generar formas y desarrollar acciones para avanzar en materia de derechos de infancia y adolescencia es un imperativo, no solo porque es un mandato del tratado y la ley arriba mencionados, sino porque el desarrollo en niñas y niños de capacidades para la participación, la escucha, el respeto, el reconocimiento de la diversidad y la resolución pacífica de conflictos sentará bases para construir un país libre de violencia.

El presente artículo de investigación tiene como objetivo valorar y documentar si la mediación en general, y la participación de niñas, niños y adolescentes en sus procesos constituyen una herramienta para garantizar sus derechos, en particular, el derecho a la participación, a tener una opinión propia, a ser escuchado, a tomar parte en las decisiones que le afectan y a una vida libre de violencia.

La inquietud por el tema surge de la experiencia desarrollada por Crecimiento Humano y Educación para la Paz A. C., tanto en procesos de mediación familiar en situación de divorcio o separación en los que se involucró la participación de niñas, niños o adolescentes como en una experiencia de mediación intergeneracional entre madres y abuelas con sus hijos/ as o nietos/as, en los que lograron generar acuerdos sobre aspectos conflictivos. La sistematización y evaluación de estos procesos está en curso, sin embargo, la autora tiene evidencia, a través de los testimonios, de que los procesos tuvieron un impacto positivo en las relaciones familiares, niñas y niños declararon ser más escuchados y tomados en cuenta por sus padres y en todos los casos, los hijos percibieron una disminución de la violencia con que eran tratados.

El presente artículo se desarrolla en cuatro apartados:1) La perspectiva de derechos de niñas, niños y adolescentes; 2)Acceso a la justicia y resolución pacífica de conflictos; 3) La mediación familiar y la 4) Relación dialógica y comunicación asertiva. $\mathrm{Al}$ final se esbozan algunas conclusiones.

\section{La perspectiva de derechos de niñas, niños y adolescentes}

La consideración de niñas, niños y adolescentes como sujetos de derechos y no como objetos de protección y control por parte del mundo adulto se ha impulsado especialmente a partir de la aprobación de la Convención sobre los Derechos del Niño -CDN o la Convención- en 1989 (Organización de las Naciones Unidas, 1990). Esta forma de concebir a la infancia y la adolescencia, que implica un cambio cultural de gran envergadura, se constituye a partir de este tratado, en un ordenamiento jurídico. La Convención tiene carácter vinculante, por lo que en los países que la han suscrito obtiene una condición de 
ley suprema, es decir, está al mismo nivel que la Constitución. Así, los Estados parte se obligan a tomar las medidas necesarias para garantizar su cumplimiento.

La Ley General de los Derechos de Niñas, Niños y Adolescentes (Ley General), promulgada en México en 2014, reconoce "a niñas, niños y adolescentes como titulares de derechos, con capacidad de goce de los mismos, de conformidad con los principios de universalidad, interdependencia, indivisibilidad y progresividad" (artículo 1).

Tanto la Convención como la Ley General establecen entre sus principios rectores "el interés superior del niño" y "el derecho a opinar, ser oído y tenido debidamente en cuenta" (Morlachetti, 2014). Reconocen además a niñas, niños y adolescentes (NNA) como sujetos capaces de tener opiniones propias y a que sean escuchadas y en consecuencia establecen el derecho a la libertad de expresión y a que se realice en las formas o modalidades que el niño quiera o requiera.

\section{Unicef reconoce en la Convención sobre} los Derechos del Niño el marco más importante para impulsar cualquier tipo de participación de las personas menores de 18 años. En realidad, el gran desafío de la Convención consiste en adecuar los principios democráticos de consenso, pluralidad, convergencia y participación para todas las personas menores de 18 años: desde la edad temprana en espa- cios como la escuela y la familia, hasta la adolescencia en espacios como la comunidad local, la sociedad y el Estado (Adorna, 1999, p. 7).

Según Adorna (1999), la participación es tanto un principio rector como un derecho establecido en la Convención y su importancia radica en diversas cuestiones que requieren ser examinadas y analizadas con cuidado: primero, hay una relación directa y de reciprocidad entre democracia y derechos de niñas, niños y adolescentes, pues los últimos se realizan en ambientes democráticos. En este sentido, el derecho a la participación de las generaciones más jóvenes desarrolla formas de convivencia basadas en el respeto mutuo y en la "aceptación del otro como legítimo otro" (Adorna, 1999, p. 8). Segundo, la participación se ejerce de manera distinta en las diferentes edades (primera infancia, infancia y adolescencia) y de ello depende en buena medida el ámbito en que se desarrolla: familia, escuela, comunidad, sociedad, Estado). Tercero, la disposición de las personas adultas y su capacidad de escuchar realmente a los niños es un elemento fundamental en la realización de sus derechos. "La falsa disyuntiva entre los derechos de los padres y los derechos de los niños (o los de los maestros 'versus' los alumnos) se resuelve en esa disponibilidad de 'escucha”" (Adorna, 1999, p. 8). 
En términos generales, existe todavía una representación social mayoritaria de niñas, niños y adolescentes como "objeto social”, es decir, no se les reconoce como sujeto, sino como "objeto pasivo de protección y cuidado" (Pérez, 1999, p. 45). Esta concepción de la niñez y la forma de relación con el mundo adulto se repite en el ámbito familiar, en el que se le asume como "beneficiaria" de las decisiones que los adultos toman "por su bien”. Como afirma Pérez (1999), las visiones hegemónicas esconden el autoritarismo de los adultos (paternalismo y verticalismo) y limitan el desarrollo del potencial que los más pequeños tienen. Con ello detienen también el desarrollo de la responsabilidad sobre los ambientes en que se desarrollan.

Cambiar esa forma de ver a niñas, niños y adolescentes por otra en la que se les reconozca como sujetos activos y se favorezca su derecho a participar, promueve un rol activo frente a su realidad, potenciando sus recursos en pro de su propio desarrollo, tanto como en el de su familia y el de su comunidad (Pérez, 1999). Esta perspectiva reconoce "a niños y adultos como sujetos sociales, en igualdad de condiciones. Por supuesto, considerando sus propias particularidades y grados de desarrollo" (Pérez, 1999, p. 45). No se asume a la niñez como preparación para etapas posteriores, sino como presente. Considerar de este modo a niñas, niños y adolescentes, lleva a democratizar las relaciones y permite que estos ejerzan sus derechos y responsabilidades, sin tener que esperar de manera pasiva y contemplativa hasta cumplir los dieciocho años.

Con base en lo anterior, si se pretende que las personas de menor edad se conviertan en adultos participativos y comprometidos con su entorno, ello debe practicarse desde edades tempranas, pues como afirma el Fondo de las Naciones Unidas para la Infancia (s/f):

La confianza y la competencia para participar se adquieren gradualmente, con la práctica. No se puede esperar que, repentinamente, los niños, al cumplir la mayoría de edad, se conviertan en adultos responsables y participativos sin ninguna experiencia previa en las habilidades y responsabilidades que ello conlleva. La participación es, por tanto, un derecho y una responsabilidad, ya que implica compartir las decisiones que afectan a la vida propia y a la vida de la comunidad en la cual se vive (párrafo 2).

2.1 El derecho de niñas, niños y adolescentes a ser escuchados

La Convención establece en su artículo 12 el derecho de niñas, niños y adolescentes, siempre que estén en condiciones de formarse un juicio propio, a contar con una opinión propia, a expresarla libremente y a que sea tomada en cuenta en función de su edad y madurez. Así mismo, con el fin 
de lograr lo anterior, se les dará "la oportunidad de ser escuchado(s), en todo procedimiento judicial o administrativo que afecte al niño, ya sea directamente o por medio de un representante o de un órgano apropiado, en consonancia con las normas de procedimiento de la ley nacional".

En la observación número 12 de la Convención, el Comité de los derechos del niño de la Organización de las Naciones Unidas (2009) desarrolla lo que implica el derecho del niño a ser escuchado. Según el numeral 22, el niño tiene "el derecho de expresar su opinión libremente”, es decir, libre de toda manipulación o influencia. El derecho a ser escuchado lleva implícito el derecho de niñas, niños y adolescentes a expresar sus opiniones, lo que obliga a los adultos responsables de escucharles a proporcionar toda la información sobre los asuntos y las posibles decisiones que les impliquen, pues solo si estos están debidamente informados podrán tomar decisiones claras (numeral 25). La observación número 12 es clara también en cuanto a la obligación de los Estados parte de garantizar este derecho (a expresar sus opiniones) "en TODOS los asuntos que les afecten" (numeral 26, p. 11). El otro elemento, establecido en la Convención es el de "tener debidamente en cuenta las opiniones del niño en función de la edad y madurez del niño", aspecto relevante también en cuanto a las responsabilidades que niños y adolescentes pueden asumir.
La observación número 12 también establece el significado y la importancia de que niñas, niños y adolescentes sean escuchados en la familia y reconoce que:

La familia en que los niños pueden expresar libremente sus opiniones y ser tomados en serio desde las edades más tempranas supone un importante modelo y una preparación para que el niño ejerza el derecho a ser escuchado en el conjunto de la sociedad. Esa manera de ejercer la labor de los padres sirve para promover el desarrollo individual, mejorar las relaciones familiares y apoyar la socialización del niño y desempeña una función preventiva contra toda forma de violencia en el hogar y en la familia (numeral 90).

Los Estados parte deberían alentar a los padres y tutores a considerar sus opiniones y a "apoyar el desarrollo de estilos de crianza que respeten el derecho del niño a ser escuchado", así como promover "programas de educación de los padres que se basen en conductas positivas..." (numerales 92 y 93). Los programas orientados a promover la participación y el derecho de niñas, niños y adolescentes a ser escuchados deben abordar algunos puntos básicos, tales como el respeto mutuo en las relaciones entre padres e hijos; la implicación y participación de estos en la toma de decisiones; las repercusiones de considerar realmente las opiniones de todos y cada uno de los 
miembros de la familia; la comprensión de las diversas etapas del desarrollo de niños y adolescentes, así como "la promoción y el respeto de la evolución de sus facultades y los modos de tratar las opiniones en conflicto dentro de la familia" (Comité de los Derechos del Niño de la Organización de las Naciones Unidas, 2009, p. 23).

La ventaja más elemental de escuchar (entrevistar) a un niño estriba en el hecho de que nadie conoce mejor que él mismo sus percepciones, sentimientos y pensamientos (Gollop, 2001). Escuchar a los niños desarrolla en ellos "sentimientos de autoestima, competencia y conexión, que son fundamentales para un ciudadano en una democracia” (Tapp y Henaghan, 2001, p. 172). No reconocer que el niño o adolescente tiene una opinión e imponer la visión de los adultos, perpetúa su consideración como "menores", como seres inferiores o incapaces.

2.2 Niñas, niños y adolescentes como sujetos de derechos: Una nueva relación de poder El reconocimiento de niñas, niños y adolescentes como sujetos de derechos implica tensión con el rol de adultos asumido tradicionalmente. A pesar de que la promulgación de la Convención está por cumplir tres décadas, se sigue considerando a la infancia y la adolescencia como incapaces o carentes respecto a los adultos. Sin embargo, para la Convención ser niño es "una forma de ser persona hoy, válida y respetable [...] una etapa de desarrollo efectivo y progresivo de la autonomía personal, social y jurídica” (Unicef, 2013, p. 9).

Considerar a los niños como sujetos, con una opinión propia, capaces de asumir responsabilidad según su nivel de desarrollo, implica una transformación en la relación de poder que no siempre los adultos están dispuestos a hacer. En entrevista realizada por Alonso (2017a), Tonucci afirma que: "escuchar a los niños es incómodo. Si se tiene en cuenta lo que nos dicen, hay que promover cambios y estos implican siempre abrir conflictos con los adultos" (párrafo 6).

Es necesario considerar que la participación infantil tiene una implicación ético-política, ya que involucrar a niñas, niños y adolescentes "pondría en tensión las lógicas de estructuración y jerarquización a las que responden los sistemas del orden social, que tienden a invisibilizar y distanciar a la infancia de las esferas de discusión pública, propiciando la exclusión en la que se ve involucrada" (Lay-Lisboa y Montañés, 2018, p. 2).

Cascón (2004) refiriéndose a los desequilibrios de poder existentes en las relaciones y en los conflictos, plantea que educar para la paz implica trastocar esa relación de poder, para pasar de un ejercicio del poder como autoritarismo a una deconstrucción de autoridad, de la obediencia y el sometimiento a la colaboración de quien “está abajo”. En los cursos y talleres con 
padres de familia es frecuente reconocer el miedo a perder autoridad, sin embargo, "no es la autoridad la que está en peligro sino el autoritarismo que, casi siempre, es justamente lo contrario" (p. 20).

Resolver los conflictos de manera pacífica requiere un reequilibrio del poder, lo que implica "enseñar a tomar poder a quien está abajo (apoderamiento) y aprender a quitar poder de quien está arriba (desobediencia) [pues] no se podrá hacer valer derechos o necesidades en un conflicto si no se sabe reequilibrar el poder y por lo tanto, no enseñarlo, será tanto como educar para la sumisión y el conformismo (Cascón, 2004, p. 20).

En el caso de la relación entre padres e hijos, los adultos juegan un papel fundamental en el apoderamiento y en el desarrollo de la confianza en sí mismos, la autoestima y asertividad. Para que el niño crezca en poder personal, autonomía y responsabilidad, es necesario un adulto capaz de confiar en él, que le acepte como una persona distinta, que piensa, siente y opina distinto, capaz de tomar decisiones y asumir las consecuencias que de ellas se deriven, de acuerdo con su nivel de desarrollo.

Parte de la dificultad para escuchar a los niños y realizar este reequilibrio tiene que ver con la resistencia de los adultos para desempeñar ese papel, con la correspondiente transformación de la relación de poder, pues como afirma Tonucci, en entrevista realizada por Alonso (2017), para que ello ocurra es necesaria la presencia de adultos dispuestos a hacer ese cambio y jugar ese papel: "para que el niño tenga derecho a decir, necesariamente el adulto tiene que ejercer su deber de escuchar" (párrafo 7).

En resumen, respetar los derechos de la niñez implica una transformación de la relación de poder basada en el reconocimiento de que "la infancia y la adolescencia son formas de ser persona y tienen igual valor que cualquier otra etapa de la vida”. En este sentido, esta etapa es concebida "como una época de desarrollo efectivo y progresivo de la autonomía personal, social y jurídica" (Cillero, 1999, p. 2). En esta perspectiva se establece la autonomía de niñas, niños y adolescentes como uno de los principios que estructuran la Convención sobre los Derechos del Niño y es justo en la promoción de esta autonomía relativa que se reconoce al niño como sujeto y se constituye como tal (Cillero, 1999).

Promover la participación de niñas, niños y adolescentes, favorecer que expresen sus opiniones libremente y tomar en cuenta sus consideraciones para la toma de decisiones no es sencillo, sin embargo, es un reto que, como se ha expuesto, representa ventajas importantes para su desarrollo y para la formación de ciudadanos responsables durante su proceso de crecimiento. Alterar la relación de poder adultocéntrica, que les limita en el desarrollo de su autonomía y poder personal, 
es quizás el reto más grande de asumir una perspectiva de derechos. Como afirman Tapp y Henaghan (2001), tal vez "sea más fácil burocrática y emocionalmente no involucrar a los niños y decirnos que al no hacerlo los estamos protegiendo de la responsabilidad de los adultos" (p. 187).

\section{Acceso a la justicia y resolución pací- fica de conflictos}

Para abordar el acceso a la justicia, Ulf Christian Eiras Nordenstahl, entrevistado por Gigena (2017), hace una diferenciación entre tres formas básicas que permiten aclarar el concepto:

a. El acceso a la justicia. Se define en términos de la justicia jurisdiccional, ubicada en el Poder Judicial tradicional y entendida como "un servicio que brinda el Estado al que muy pocas personas pueden acceder" (Gigena, 2017, p. 126). Se desarrolla o ejerce a través de métodos heterocompositivos, cuya lógica se ubica en un juicio y en el hecho de que un juez, como "tercero imparcial decide la controversia” (Arellano, 2017, p.5).

b. El acceso a la justicia, se identifica con lo que se ha denominado como justicia alternativa y se desarrolla a través de mecanismos alternos a la solución tradicional de controversias, distintos a la tutela jurisdiccional, pues aunque con frecuencia se ponen en marcha por un conflicto que ha llegado a los tribuna- les, la solución se genera por la voluntad de las partes y no por la decisión de un juez (Silva y Martínez, 2019). Se lleva a cabo mediante métodos autocompositivos que promueven el protagonismo de las partes en conflicto y favorecen que sean ellas mismas quienes generen la solución a través de acuerdos que suelen contar con mayor legitimidad, ser más durables y tener mayores posibilidades de ser cumplidos que aquellos que son impuestos por un juez.

c. Acceso a justicia, a la que se considera "como valor y no como servicio judicial”; implica caminos alternativos a las formas tradicionales de resolver los conflictos, pero implica sobre todo la experiencia -y la comprensión para las personas, de "que se está llegando a una solución justa” (Gigena, 2017, p. 127).

De acuerdo con Eiras Nordenstahl, la justicia jurisdiccional y la alternativa (incisos a y b) se constituyen como dos sistemas diferentes a los que toda la población debería tener acceso. El historiador y abogado es enfático al plantear que el acceso a la justicia debe ser una realidad para todos y habría que trabajar porque los sectores más vulnerables de la población puedan acceder a los servicios de la justicia tradicional; cuestiona los discursos que asocian la justicia y los medios alternativos como la única posibilidad de acceso a la justi- 
cia por parte de los sectores vulnerables y pugna porque ello deje de ser así (Gigena, 2017). Sin embargo, es innegable que estos mecanismos forman "parte integrante del derecho de acceso a la justicia”, especialmente por las dificultades de acceso real y efectivo a un juicio por parte de amplios sectores de la población, dados sus costos económicos, las dificultades que conlleva y la sobresaturación del sistema jurisdiccional. Así, en los últimos tiempos, "ha tomado fuerza la idea de considerar a los Mecanismos alternativos al proceso judicial (MAPJ), [...] como parte integrante del derecho de acceso a la justicia, e incluso como la respuesta más apropiada para la resolución de muchos conflictos sociales e interpersonales" (Arellano, 2017, p. 4).

En México, a partir de las reformas constitucionales del 2008, específicamente al artículo 17, se reconoció como derecho humano la posibilidad de que los conflictos puedan resolverse mediante los mecanismos alternativos de solución de controversias, siendo la mediación uno de ellos. La mediación, como uno de los mecanismos alternativos de solución de conflictos (MASC), se encuentra en un mismo plano constitucional y con la misma dignidad que la tutela judicial y tiene como objeto idéntica finalidad, que es, resolver los diferendos entre las personas.

No se habla, por ende, de un procedimiento arbitrario o sujeto a caprichos de las personas en conflicto, sino de un me- canismo jurídico y profesional que promueve la participación más activa de las partes para encontrar formas de relacionarse entre sí. En términos generales, la justicia alternativa y/o los MASC se han instituido como un sistema de servicios de mediación, conciliación o arbitraje que se ofrecen desde el Estado y quienes se han desempeñado como mediadores y una cantidad importante de literatura dan fe de la forma como estos procesos -y la generación de acuerdos satisfactorios para ambas partes- contribuyen en el acceso a justicia (inciso c), al convenir las partes en soluciones que responden a sus necesidades e intereses y que consideran justas.

Sin embargo, para avanzar en el acceso a justicia, es menester promover y desarrollar formas pacíficas de resolución de conflictos alternativos a la violencia y no solo a las formas de la justicia tradicional en todos los ámbitos de la vida. Como plantea Hernández Tirado (2016), el contexto actual en el que prevalece la violencia en todos sus ámbitos, requiere "líneas de convergencia en la solución de conflictos alejadas de la violencia", lo que confluye con "el germen de una ética por acuerdo, basada en valores universalmente reclamados, como son la justicia, la igualdad, la libertad, la paz, la tolerancia y la solidaridad, a los que la mediación puede dar respuesta de forma práctica y eficaz" (p. 89).

La justicia, independientemente de la construcción que se ha hecho de este con- 
cepto desde el ámbito jurídico, es en esencia un valor que regula o busca regular la interacción humana. Así, una medida, una decisión o un acuerdo es justo en la medida en que aporta en la solución de su problemática. Podría asumirse en este sentido la visión de los primeros practicantes cristianos, en los que cada persona aportaba según sus capacidades y recibía según sus necesidades. Si los problemas que se generan en la interacción humana se atendieran con tal concepto de justicia, las personas y las comunidades tendrían una vivencia cotidiana o una experiencia justa "de proximidad", una justicia "cotidiana” (Hernández-Tirado, 2016). Esto requiere de procesos de educación para la paz que permitan y faciliten el desarrollo de habilidades para resolver conflictos de manera pacífica en todos los ámbitos de la vida cotidiana: la familia, la escuela, el barrio, el centro de trabajo, etcétera.

El acceso de niñas, niños y adolescentes a la justicia es fundamental a través de la justicia tradicional y también de la justicia alternativa. Con la incorporación de la perspectiva de derechos se convierte en un imperativo resolver "la justicia" bajo la consideración del interés superior del niño y el adolescente, lo que obliga a los jueces a tomar decisiones en función de dicho principio, del mismo modo que exige a quienes fungen como facilitadores de MASC, constituirse en vigilantes del interés superior siempre que los conflictos -o los acuerdos- involucren personas menores de edad. Así mismo, en los casos en que sea posible la participación de niñas, niños y adolescentes como protagonistas en la construcción de acuerdos sobre asuntos que les implican, de modo que su voz sea escuchada y sus necesidades sean planteadas por ellos mismos, será siempre responsabilidad y deber de la persona facilitadora garantizar su bienestar a través de la observancia del interés superior. El interés superior del niño y el adolescente se constituye así en el criterio de lo justo para las personas menores de dieciocho años, toda vez que las decisiones que se tomen por un tercero (juez) o se construyan a través de medios alternos -con o sin su participación- deben tomar en cuenta sus necesidades, lo que sea mejor para su bienestar y desarrollo.

La Convención sobre los Derechos del Niño es un paso importante en la búsqueda de acceso a justicia para niñas, niños y adolescentes, pues insta a reconocerles como sujetos de derechos y como interlocutores válidos, lo que potencia la posibilidad de que sus necesidades, sus opiniones y su participación sean incorporadas en la resolución de conflictos sobre asuntos que les afectan. Aunque no lo dice con esas palabras, el tratado es un impulso al acceso a justicia para niñas, niños y adolescentes, pues convierte en un imperativo que las decisiones sobre temas que les afectan sean justas, al tener siempre como guía 
el interés superior, tomar en cuenta sus necesidades y facilitar el ejercicio de sus capacidades, según su nivel de desarrollo.

Para avanzar en el acceso a justicia, es menester promover y desarrollar formas pacíficas de resolución de conflictos alternativos a la violencia y no solo a las formas de la justicia tradicional en todos los ámbitos de la vida. Como plantea Hernández Tirado (2016), el contexto actual, en el que prevalece la violencia en todos sus ámbitos, requiere "líneas de convergencia en la solución de conflictos alejadas de la violencia”, lo que confluye con "el germen de una ética por acuerdo, basada en valores universalmente reclamados, como son la justicia, la igualdad, la libertad, la paz, la tolerancia y la solidaridad, a los que la mediación puede dar respuesta de forma práctica y eficaz” (p. 89).

Desde la perspectiva de la educación para la paz se promueve la resolución de los conflictos a través de medios pacíficos, lo que implica un compromiso por la noviolencia, ${ }^{2}$ que se refiere por una parte a renunciar al ejercicio de la violencia en todas sus manifestaciones y por otra, a la generación de acciones positivas y propositivas en favor del respeto de la dignidad y los derechos humanos (2004). Asumir

2 Se respeta la decisión de los autores (Cascón, 2004; Cascón y Papadimitriou, 2004 y Papadimitriou y Romo, 2005) de manejar el término noviolencia o noviolento como una forma de visibilizar un nuevo concepto que no se refiere solo a decir no a la violencia, sino a la implicación activa a favor de la paz con justicia y derechos humanos. una perspectiva noviolenta en la relación con niñas y niños es un reto doble: implica el reto general de renunciar a la violencia, ya de por sí difícil; y cambiar una representación social dominante sobre la infancia, tanto en la consideración de que su desarrollo es un asunto privado, como en la legitimación del maltrato y la violencia como formas de educar y corregir a las y los más pequeños. El primer paso para avanzar en la resolución pacífica (o no violenta) de conflictos, será precisamente el conocimiento del conflicto y la decisión de asumirle con una perspectiva positiva.

\subsection{Perspectiva positiva del conflicto}

Existen diversas definiciones de conflicto. En términos generales, se identifica como la existencia de necesidades o intereses divergentes entre dos o más personas o grupos, que pueden ser o percibirse como irreconciliables. También se define como un "proceso de incompatibilidad entre personas, grupos o estructuras sociales, mediante el cual se afirman o perciben (diferencia entre conflicto real y falso conflicto) intereses, valores y/o aspiraciones contrarias” (Asociación Matiz, Educación en valores, 2015, p. 14).

El conflicto es consustancial a la naturaleza humana y no es bueno ni malo en sí mismo. Lo que ocurra con él depende de la forma como evoluciona según la manera en que se interviene en él, haciendo que escale y se agudice, o bien aprovechándo- 
lo como oportunidad de cambio y crecimiento (Suares, 2008; Cascón, 2004; Parra, 2014; Martínez Munguía, 1999).

Suares (2008) define el conflicto como un proceso interaccional, en el que participan dos o más partes (personas o grupos), con predominancia de interacciones antagónicas sobre las atrayentes. Se trata de interacciones en las cuales las personas que intervienen lo hacen como seres totales con sus acciones, sus pensamientos, sus afectos y sus discursos", a veces cargados de agresividad. Un aspecto fundamental, que aplica también en los conflictos en que participan niñas, niños y adolescentes, es que el conflicto es un proceso co-construido, en el que la interacción entre las partes lo alimenta y le da vida; es también un proceso complejo (Suares, 2008, p. 78).

El conflicto forma parte de la naturaleza humana y se manifiesta en todas las relaciones y sociedades y contiene siempre posibilidades de construcción y de destrucción (Romero, 2002). Para Girard y Koch (1997), el conflicto es "una condición humana orgánica" y "un suceso potencialmente positivo" (p. 47), por lo que valorarlo positivamente y comprenderlo a través del análisis de las necesidades, los intereses y las emociones que están implicadas en él es un paso necesario poder resolverlos o transformarlos de manera positiva.

El conflicto, visto de una manera positiva, es una oportunidad para reconocer y enriquecernos de las diferencias; es una palanca de cambio, pues indica, entre otras cosas, la necesidad de modificar reglas, o flexibilizar estructuras rígidas; representa una posibilidad privilegiada para aprender de sí mismo y de los otros y para generar acuerdos que permitan una convivencia más sana y pacífica (Cascón, 2004).

\subsection{Conflicto entre madres/padres e hijos/as}

$\mathrm{Si}$ el conflicto implica la existencia de intereses o necesidades entre dos o más personas que son o se perciben como incompatibles, las relaciones entre padres e hijos no son la excepción. De acuerdo con Parkinson (2005), "frecuentemente los padres dan por supuesto que las necesidades y sentimientos de sus hijos coinciden con las propias, pero puede que no sea así" (p. 180). Los padres reconocen cómo la mediación les ayuda a comprender mejor a sus hijos y a tomar en cuenta tanto sus propias necesidades y sentimientos como los de sus hijos. Identifican en la mediación un recurso para favorecer una educación más centrada en los hijos, logrando separar los sentimientos de enojo y resentimiento hacia la expareja y dejando de proyectarlos sobre los hijos (Parkinson, 2005). Para comprender y atender de manera eficaz los conflictos, es necesario comprender que niñas, niños y adolescentes tienen experiencias distintas y suelen tener un enfoque muy distinto al de los adultos. "Sus opiniones sobre sus propios sentimientos pueden ser sustancialmente 
contrarios a lo que sus padres piensan que están sintiendo acerca de una situación" (Tapp y Henaghan, 2001, p. 172). Por eso es tan importante escucharles, abrir los espacios y crear los ambientes necesarios para que expongan con libertad sus necesidades, pensamientos y emociones.

Con frecuencia los adultos utilizan la fuerza (y la violencia) porque asumen que hay que controlar y someter a los niños. En términos generales, la violencia está legitimada como forma de "resolver" conflictos, en las relaciones entre adultos y niños, pues se sigue concibiendo a los hijos como "propiedad" de los padres y la utilización de la violencia se justifica con fines "educativos". Esta visión se expresa cotidianamente en frases como "yo educo a mis hijos como yo quiero", "nadie va a decirme cómo educarlos", "le pego porque le quiero", "más vale una nalgada a tiempo”, etcétera. Culturalmente está legitimado "resolver" controversias con los hijos por la fuerza o con formas violentas (Plitt y Cadavid, 2011).

Como sostienen Plitt y Cadavid (2011): "Para encontrar una solución pacífica al conflicto es necesario no solo tomar en consideración al otro sino reconocerlo como interlocutor válido que posee iguales derechos y libertades” (p. 236). En la medida en que somos capaces de empatizar con el otro y percatarnos de sus intereses y necesidades, podemos llegar a acuerdos que retomen los de ambos. Es desde ese espacio de entendimiento y comprensión mutua, basada en el respeto y la empatía, que "puede abrirse el espacio para una concertación, para un acuerdo de voluntades sin vencedores ni vencidos" (Plitt y Cadavid, 2011, p. 236). Este espacio se conforma cuando se establece una relación dialógica entre padres e hijos, una relación fundada en el respeto y la confianza, en el reconocimiento del otro como alguien diferente.

\subsection{Niveles de intervención en conflictos}

Cascón (2004) define tres niveles en los que se trabaja la creación de ambientes pacíficos y el abordaje positivo de los conflictos: provención, negociación y mediación. En las edades más tempranas, la mayor parte de los procesos se concentran en el nivel de la provención, desde el que se buscan crear los ambientes y desarrollar las competencias necesarias para resolver los conflictos en el momento en que surgen. Las personas aprenden a conocerse y afirmarse a sí mismas, así como a reconocer, respetar y aceptar a los otros. Paradas de esta forma en sus relaciones interpersonales, las personas y los grupos generan confianza y desarrollan capacidades para la comunicación efectiva y el desarrollo de la cooperación. Las personas y los grupos tendrán la capacidad de resolver sus conflictos mediante la negociación, a través de actitudes de cooperación, pues tendrán la posibilidad de comunicarse y generar 
acuerdos satisfactorios para las partes intervinientes por sí mismas. En el caso de la mediación, como se desarrollará más delante, requerirán la ayuda de un tercero que facilite el proceso de comunicación, la activación de actitudes de cooperación y la generación de acuerdos satisfactorios para las partes involucradas (Cascón, 2004).

La cooperación es una actitud y una forma de actuar en la que lograr los objetivos es muy importante, pero también lo es la relación. Esto quiere decir que, al dar importancia a ambos aspectos (los fines y la relación), las personas o los grupos tratarán de resolver el conflicto sin renunciar a aquellos aspectos que les son importantes, pero con el cuidado necesario para no dañar o violentar al otro. Desde la perspectiva de la noviolencia, este aspecto está implícito en la filosofía en que se sustenta, según la cual, "el fin y los medios tienen que ser coherentes” (Cascón, 2004, p. 11). Si lo que se persigue es la construcción de la paz, esto nunca podría hacerse con medios violentos. Si el objetivo fuera educar al hijo en la libertad y la responsabilidad, ello no podría desarrollarse con medios autoritarios y/o que opriman su capacidad de expresión y desarrollo. Si el fin es promover la participación infantil, no podría hacerse jamás negando a los niños ese derecho y posibilidad.

La cooperación o colaboración "implica un intento de trabajar con la otra persona para encontrar alguna solución que satis- faga plenamente los intereses de ambas personas" (Mirabal, 2003, p. 58). Ello exige un análisis profundo del conflicto, a fin de identificar los intereses y las necesidades de ambas personas, pues solo así podrán avanzar en generar una opción que sea satisfactoria para ambos. La cooperación puede ser también la indagación sobre la perspectiva del otro y la búsqueda de alternativas a un problema común (Mirabal, 2003). La cooperación es un modelo de interacción "en el que solo sirven soluciones gano-ganas" (Cascón, 2004, p. 11).

La resolución pacífica de conflictos se constituye como un recurso para garantizar el derecho de niñas, niños y adolescentes a una vida libre de violencia, pues la cooperación sería el enfoque educativo con el que se acompañe su crecimiento en la familia, la escuela y la comunidad. Por una parte, a través de espacios de prevención, que generen el reconocimiento y el respeto por la diversidad, en los que los miembros del grupo ven respetado su derecho a tener una opinión propia y a expresarla, con apertura al diálogo y a la búsqueda de consensos. El problema es que, para facilitarlas en niñas, niños y adolescentes, los adultos tienen que haberlas desarrollado y vivirlas como parte de su práctica cotidiana.

En segundo término, para el abordaje de conflictos que han escalado y en los que las partes tienen necesidad de un tercero que facilite el proceso comunicativo y la 
generación de acuerdos, es a través de la mediación que se promueve el desarrollo de estas capacidades como el vehículo a través del cual los intervinientes en el conflicto podrán escucharse, reconocerse y generar alternativas.

\section{Mediación familiar}

La mediación es una herramienta para la resolución de conflictos que sirve en aquellos casos en los que las personas o grupos en conflicto han agotado las posibilidades de resolverlos por sí mismos, "o en los que la situación de violencia o de incomunicación impiden que puedan hacerlo" (Cascón, 2004, p. 24). Cuando esto ocurre, las partes implicadas pueden solicitar la intervención de un tercero (al que se llama mediador/a) que les ayude a restablecer la comunicación y que favorezca la creación del "espacio y clima adecuados para que puedan hacerle frente (al conflicto) y resolverlo", mediante la construcción de "un proceso justo" (Cascón, 2004, p. 24). La mediación, como medio pacífico de resolución de conflictos, tiene su base en la cooperación, más que en la competencia o el enfrentamiento y tiene como objetivo que las personas puedan comunicarse de manera efectiva, a través de un diálogo respetuoso desde el que puedan exponer sus necesidades, intereses y sentimientos. El papel de la persona mediadora será entonces facilitar que esa comunicación fluya, "deshaciendo lo nudos" en los que las personas se atoran cuando aparecen los conflictos o cuando se tienen disputas (García y Bolaños, 2010).

La mediación es reconocida como uno de los medios alternos de solución de conflicto (MASC). La Ley de Justicia Alternativa del Estado de Chihuahua, define la mediación como el "mecanismo por el cual los usuarios, de manera voluntaria, acuden ante un facilitador, para buscar la construcción de un acuerdo o convenio satisfactorio que ponga fin a una controversia, de manera parcial o total” (artículo 5). Sin embargo, más allá del sistema judicial y los sistemas de justicia alternativa, la mediación es, como se había mencionado arriba, una opción de vida, una forma de relacionarse con los otros que parte de la renuncia a la violencia y de la búsqueda de alternativas pacíficas para solucionar conflictos.

Para introducir el concepto de mediación familiar, es menester antes definir el de familia. Si bien, en el mundo occidental sigue prevaleciendo una definición tradicional, basada en el componente heteronormativo y en la constitución de un núcleo conformado por padre, madre e hijos, es evidente que no es el único y que, a fin de responder a la realidad, es indispensable reconocer la diversidad de grupos familiares existentes, por lo que resulta más adecuado utilizar el término familias y asumir que "más que un solo tipo de familia o una 'familia ideal', existen 'muchas familias' que representan diversas formas 
de crecer, convivir y relacionarse" (Oliva Gómez y Villa Guardiola, 2014, p. 13). Como afirma Gras-Velázquez (2014):

la institución familiar se ha definido a través del tiempo como aquella que sigue el modelo nuclear heteronormativo, y aquellos modelos de familia que no siguen este modelo (ya sean parejas del mismo sexo o familias compuestas por una madre soltera o un padre soltero, entre otras) se definen en relación a esta generalización heterosexual. Como resume Peter M. Nardi "la familia nuclear, tradicional ha sido el modelo dominante por razones políticas" y ha "estructurado muchas normas legales y sociales en nuestra cultura" [...] La familia nuclear heteronormativa sigue siendo el modelo de organización social más extendido y asimilado culturalmente (Gras-Velázquez, 2014, p. 15).

La Comisión Nacional de los Derechos Humanos, en aras de promover su protección jurídica y de difundir los derechos, obligaciones y deberes de sus integrantes, reconoce los siguientes tipos de familia:

- Nuclear sin hijos: Dos personas.

- Nuclear monoparental con hijas(os): Un solo progenitor(a) con hijas(os).

- Nuclear biparental: Dos personas con hijos(as).

- Ampliada o extensa: Progenitoras(es) con o sin hijos y otros parientes, por ejemplo, abuelas(os), tías(os), primos(as), sobrinos(as) entre otros.

- Compuesta: Una persona o pareja, con o sin hijos(as), con o sin otros parientes, y otros no parientes.

- Ensamblada: Persona con hijos(as), que vive con otra persona con o sin hijos(as).

- Homoparental: Progenitoras(es) del mismo sexo con hijas(os).

- Heteroparental: Mujer y hombre con hijas(os).

- Sin núcleo: No existe una relación de pareja o progenitoras(es) hijas(os) pero existen otras relaciones de parentesco, por ejemplo: dos hermanas(os), abuela(o) y sus nietas(os), tíos(a) y sobrinas(os), etcétera.

- De acogida: Aquella con certificación de la autoridad para cuidar y proteger a niñas, niños y adolescentes privados de cuidados parentales, por tiempo limitado.

- De origen: Progenitoras(es) tutores(as) o persona que detente la guarda y custodia de niñas, niños y adolescentes con parentesco ascendente hasta segundo grado (abuelos/as).

- De acogimiento preadoptivo: Aquella que acoge provisionalmente a niñas, niños y adolescentes con fines de adopción.

- Sociedades de convivencia: Dos personas de igual o distinto sexo que establecen un hogar común con voluntad de 
permanencia y ayuda mutua (con o sin hijos, hijas).

En síntesis, la familia puede definirse, en los términos de Giddens (1998), como "un grupo de personas directamente ligadas por nexos de parentesco", sea por consanguinidad o por la existencia de un vínculo legal, lo que implica que antes de ser un concepto jurídico, es un concepto sociológico (Carbonel, 2006). Independientemente de la diversidad en su tipología, en las familias siguen llevándose a cabo las tareas de reproducción de los seres humanos y es en ellas, en términos generales, donde se generan los bienes y servicios para ello; es también un espacio fundamental en la construcción de la identidad y en el desarrollo de la subjetividad de las personas (Astelarra, 2007). En las familias, hasta los tiempos actuales, descansan "aspectos fundamentales en la reproducción de la cultura y la transmisión de saberes para la vida, como el aprendizaje de la lengua, los hábitos de alimentación y crianza, las formas de ver y relacionarse con otros y de resolver conflictos" (Almada, 2012, p. 53).

La mediación familiar es entonces un campo basto que puede desarrollarse para abordar conflictos y generar acuerdos en todos los tipos de conformaciones familiares arriba expuestos. Sin embargo, la mayor parte de la práctica y la literatura sobre mediación familiar se ha concentrado en los conflictos relacionados con procesos de separación o divorcio y en la generación de acuerdos sobre aquellos aspectos en los que requieren convenir. Al haber estado la mediación familiar en buena medida circunscrita a los sistemas de justicia alternativa, su desarrollo principal ha estado vinculado a los casos que se judicializan o bien, a la prevención de que ello ocurra.

Ripoll-Millet (2000) hace una abundante recopilación de definiciones de mediación familiar, en las cuales impera el énfasis en conflictos de pareja: para definir los términos de la pensión alimenticia o la custodia de los hijos; cuando una pareja en proceso de divorcio pide de manera voluntaria la ayuda de un tercero que les ayude a dirimir sus diferencias. Se define la mediación familiar como "una forma alternativa de resolver conflictos propios de la ruptura familiar", entre los que se incluye la distribución de los bienes, la residencia y custodia de los hijos o el establecimiento de la pensión alimenticia (Ripoll-Millet). Esta forma tradicional de definir la mediación familiar ha estado estrechamente relacionada con las necesidades del sistema judicial y con el desahogo de los casos de divorcio contencioso que se vuelven prolongados e implican un desgaste grande para la pareja y los hijos y representan también una sobresaturación del sistema.

La mediación de conflictos de separación o ruptura tiene un aporte importante en la generación de ambientes más saludables y 
pacíficos en el ámbito familiar, pues reduce "la irracionalidad de las partes". Al disminuir los ataques personales, generar formas más efectivas y asertivas de comunicación y generar acuerdos sobre aspectos esenciales, la violencia disminuye, tanto entre los cónyuges (muchas veces atestiguada por los hijos), como en relación con los hijos que, con frecuencia forman parte de la disputa y son víctimas del jaloneo entre sus progenitores (Ripoll-Millet, 2000).

La participación de niñas, niños y adolescentes en mediación familiar se ha centrado en la consideración de su opinión en procesos de separación o divorcio entre los padres (Suares, 2015; Romero, 2016). Además de vincular la mediación entre padres e hijos a la existencia de procesos de separación o divorcio, los pocos casos en que las publicaciones dan cuenta de la participación de hijos o hijas en el proceso, es cuando estos son ya adolescentes. Al tratarse de una etapa de transición, se identifica un momento de crisis en la familia, ya que los lenguajes de unos y otros pueden percibirse como "incompatibles" o "incomprensibles" y la diferencia generacional entre padres e hijos parece agudizarse (García y Bolaños, 2010).

Existen diferentes posiciones sobre la incorporación de los niños a los procesos de mediación. Por una parte, desde una perspectiva tradicional se sugiere trabajar con los padres y expertos, manteniendo alejados a los menores de edad; por otra, desde una óptica más nueva y revolucionaria, se aboga por su inclusión en mediación (Valero Matas, 2010). El enfoque clásico, se basa en la idea (tomada de la teoría de la personalidad) de que "los niños tienen la dificultad para comprender de manera racional lo abstracto y conceptos complejos”, lo que serán capaces de hacer una vez que alcancen la adolescencia. Derivado de esta visión, se concibe a los niños como "incompetentes para afrontar la realidad y tomar decisiones racionales”. Quienes abogan por la no inclusión de los niños en la mediación argumentan que son vulnerables y que hay que alejarles del conflicto -y, por tanto, del proceso de mediación. Finalmente, la argumentación sobre la no participación de los niños plantea claramente la visión del poder, pues "dotarlos de igual fuerza en el proceso significa devaluar la autoridad de los padres" y depositar en ellos una responsabilidad "que no puede ser compartida con los menores" (Valero Matas, 2010, pp. 90-91). Sin embargo, esta argumentación es una forma de "garantizar la voluntad del adulto en detrimento de los menores", definirles como incapaces "es el instrumento de los adultos para controlar al menor y someterlo a sus propios intereses” (p. 97).

En sentido contrario, se ubican quienes defienden con radicalidad dar voz a niñas, niños y adolescentes, lo que se argumenta en dos aspectos básicos. El primero, de tinte jurídico, a partir del cual se les reco- 
noce como sujetos de derechos y se establece el derecho de las personas menores de dieciocho años a participar en los asuntos que les afectan, de manera particular en los procedimientos relacionados con conflictos familiares. El segundo, de corte social, se define como "el mejor interés"; que surge del hecho de que las situaciones de ruptura detonan cambios y caos en el entorno familiar, a menudo los adultos entran en procesos de confrontación y "en ese ir y venir, el infante pasa de largo por el mundo de los progenitores" (Valero Matas, 2010, p. 93). Según una investigación realizada por Dowling y Barnes (2000, citado en Valero Matas, 2010), con un grupo de niños de entre 8 y 14 años, todos, sin excepción, "demandaban ser escuchados y tener oportunidad de compartir con sus padres sus sentimientos de alegría, tristeza, esperanza, amor" (p. 93). Ninguno de los niños participantes en el estudio había tenido acceso a sus padres y a exponer sus necesidades antes de que se generaran los acuerdos de divorcio, lo que muestra la necesidad de involucrarles para que planteen y defiendan sus propios intereses (Valero Matas, 2010).

Algunos de los motivos más importantes para impulsar la participación de los niños y escucharles en la mediación, serían: a) implica el reconocimiento a la dignidad básica de los niños y su participación en sociedad sujeta a derecho, $b$ ) resulta importante de cara a su desarrollo; y su participación impacta de manera positiva en su autoestima y su desempeño psicológico; c) potencia la autosuficiencia; $d$ ) su participación en el proceso exige explicarles la situación y con ello reducir sus angustias y preocupaciones; $e$ ) contar con la información y explicar la situación a los niños les facilita adaptarse a los cambios; y f) el hecho de que los padres escuchen a sus hijos puede amainar la confrontación y las controversias, favoreciendo que el proceso fluya (Valero Matas, 2010, p. 92).

Los dos aspectos básicos en defensa de la participación infantil (que es un mandato legal y lograr el mejor interés para el niño) en mediación podrían resumirse en la importancia atribuida por Suares (2015), quien valora la incorporación de los niños en la mediación familiar, tanto por razones legales que aluden a la Convención sobre los Derechos del Niño, como por la relevancia de recuperar su visión. Romero (2016) expone con amplitud la importancia de considerar el interés superior del niño como elemento central en la mediación, lo que implica una serie de derechos, entre los que se encuentra el de expresar sus opiniones, deseos y necesidades, ser escuchados y participar en las decisiones que les afectan.

A partir de la implementación de un proyecto de participación de niñas, niños y adolescentes en los procesos de mediación en Nueva Zelanda, Valero Matas (2010) ha sintetizado algunos de los principales 
aportes de que su voz sea escuchada y tomada en cuenta:

La incorporación de los niños a la mediación reduce el conflicto familiar y proporciona la triangulación de las relaciones entre el infante y sus progenitores o tutores. Siendo la figura del mediador un agente facilitador y dinamizador de acuerdos. Dando voz a los menores se generan individuos autónomos que sepan tomar decisiones. Su participación aportó soluciones más rápidas, consensuadas y atenuaron las consecuencias. Un $40 \%$ de los niños colaboradores en el proyecto piloto se convirtieron en piezas angulares en la resolución satisfactoria del conflicto parental (Valero Matas, 2010, p. 95).

Lo hasta aquí expuesto sobre la participación de niñas, niños y adolescentes en mediación familiar se ha ceñido a las situaciones de separación o divorcio de los padres; sin embargo, la mediación en el ámbito de las familias es mucho más amplia y puede promoverse en diversas situaciones y entre diferentes actores dentro del núcleo familiar. Se aprecia entonces la necesidad de ampliar las definiciones conceptuales sobre diversos tipos de mediación que se desarrollan dentro del ámbito de lo familiar y lo que tradicionalmente se ha nombrado como mediación familiar debería acotarse a "mediación de pareja".
Para Romero (2019) es comprensible que se asocie la mediación familiar con situaciones de matrimonios en proceso de divorcio, pues ha sido el conflicto que más se ha tratado en mediación. Sin embargo, es importante ampliar la perspectiva y asumir que no es el único tipo de conflicto familiar. De hecho, él como mediador reconoce que "uno de los ámbitos que más solicitudes deintervención se nos presenta a los mediadores, es el de la mediación familiar intergeneracional" (Romero, 2019, párrafo 1), en la que, si bien se ha dado énfasis a los procesos entre hijos adultos y sus padres adultos mayores, cabe también la mediación entre los padres y sus hijos durante la infancia y la adolescencia.

De acuerdo con García y Bolaños (2010), la mediación intergeneracional es aquella que se relaciona con "los conflictos relacionados con dos generaciones adultas que conviven en el mismo domicilio por intereses recíprocos y, en principio, sin una necesidad expresa de cuidados por enfermedad o dependencia” (p. 67). Según este enfoque, esta mediación sería entre generaciones de adultos, sin embargo, Romero (2019) establece que la mediación familiar intergeneracional

[T]rata de mediar en los conflictos que hayan surgido entre padres o tutores con sus hijos menores y que han llegado a tal punto de enconamiento o reiteración que ven necesaria la actuación de 
un tercero que pueda reestablecer o facilitar el diálogo entre ellos o, al menos dar las herramientas necesarias a las partes interesadas para tratar de reestablecerlo (párrafo 3).

Según esta concepción, la mediación familiar intergeneracional tiene como destinatarios a padres, madres o tutores con hijos en edad de infancia o adolescencia que atraviesen por dificultades en la convivencia, por problemas de comunicación o un establecimiento inadecuado de los roles; niñas, niños o adolescentes con problemas de relación con sus padres, o bien, "personas adoptadas o en régimen de acogimiento familiar y sus familias biológicas o adoptivas o de acogimiento" (Romero, 2019, párrafo 4).

Este tipo de mediación se plantea algunos objetivos, tales como: abrir un espacio neutral e imparcial en el que las partes enfrentadas puedan dialogar; gestionar los conflictos entre padres e hijos, favoreciendo la comprensión de la otra parte y su perspectiva del conflicto; y buscar un acuerdo, aunque sea parcial, sobre alguna de las situaciones conflictivas. Generar una dinámica de comunicación y facilitar la experiencia de diálogo es el objetivo que permitirá el éxito en la mediación. En este sentido, es fundamental que las partes tengan claro, en especial los menores de edad, "que sus argumentos van a ser oídos $y$ tenidos en cuenta y que no se van a per- mitir comentarios despectivos ni posicionamientos dominantes o agresivos, que el diálogo y las argumentaciones que se hagan con respeto hacia el otro, van a ser tratadas por igual” (Romero, 2019, párrafo 5). Este aspecto es fundamental en cualquier mediación, de modo que las partes se sientan en confianza y la comunicación pueda realmente fluir y ser efectiva.

La familia es un espacio en el que se expresan y reproducen diversas formas de violencia. Las relaciones asimétricas y las prácticas patriarcales de control hacia las mujeres y los niños por medios violentos es una práctica cotidiana. La relación entre personas adultas y menores de edad se basa, en términos generales, en la asimetría de poder, al encontrarse los más pequeños en condición de dependencia e incluso de sujeción jurídica debido a la patria potestad. La violencia "es una forma de ejercer poder sobre otra persona o grupo que se encuentra en una situación de inferioridad o subordinación" (Pérez Contreras, 2013, p. 4).

Los datos de Unicef (2017) sobre la violencia en las vidas de niñas, niños y adolescentes como una situación habitual son alarmantes. Por citar algunos, entre los niños de 2 a 4 años en el mundo, 75 \% (300 millones) son disciplinados con violencia por parte de sus padres o cuidadores; $60 \%$ reciben castigos físicos; de los niños menores de 5 años, $25 \%$ vive con una madre 
que es víctima de violencia por parte de su pareja.

En México, la Ley General de Acceso de las Mujeres a una Vida Libre de Violencia, en su artículo 8, plantea "evitar procedimientos de mediación o conciliación, por ser inviables en una relación de sometimiento entre el agresor y la víctima”; así como, "favorecer la separación y alejamiento del agresor con respecto a la víctima”. Esta disposición, dirigida hacia las mujeres, resulta aplicable a niñas, niños y adolescentes. La mediación no sería un mecanismo viable, entonces, en caso de que su ejercicio pueda poner en riesgo a quien se encuentra en posición de desventaja o cuando no se hayan generado las condiciones necesarias para una conversación dialógica, en la que las personas intervinientes puedan reconocerse mutuamente como sujetos, lo que habría implicado, inevitablemente, haber trabajado previamente en lograr equilibrio en la relación de poder.

Existen dentro de la práctica y la teoría de la mediación, posiciones diferenciadas al respecto. De acuerdo con Suares (1996):

Hay diferentes opiniones en cuanto a la llamada "violencia doméstica". Algunos autores sostienen que son casos que deben ser excluidos de los procesos de mediación, en tanto que otros han investigado los "buenos resultados" obtenidos. Esta valoración de buenos resultados tiene que ver con una sensible disminución de "nuevos actos" de violencia en los casos que han sido mediados (p. 65).

Sara Cobb (1997), la creadora del modelo circular-narrativo en mediación, sistematizó treinta sesiones de mediación y, entre otras conclusiones, afirma que a través del proceso, "la violencia se somete al discurso de la mediación misma” (p. 397). Por su parte, Munuera Gómez y Blanco Larrieux (2011) se preguntan si la violencia doméstica puede ser materia de mediación y plantean que "la respuesta no es ni sencilla ni uniforme” (p. 32); encuentran que:

La mediación puede ayudar a resolver determinados casos de violencia doméstica, pues está demostrando ser eficaz para tratar la violencia en determinados contextos. Donde a pesar de las medidas adoptadas actualmente por las administraciones los casos de violencia siguen aumentando, se deben buscar nuevas medidas seleccionando los casos donde la mediación puede ser efectiva (Munuera Gómez y Blanco Larrieux, 2011, p. 37).

En el caso de la participación de niñas, niños y adolescentes en mediación, será factible cuando puedan garantizarse su bienestar y sus derechos, lo que será posible únicamente "dando pleno respeto al principio del interés superior del niño” y asumiéndole "como eje vertebral en todo 
ámbito de cuestiones que tengan relación con los intereses de los niños y niñas" (Alarcón Cañuta, p. 12).

\section{Relación dialógica y comunicación asertiva}

Para la definición del tipo de relación que se requiere generar en los procesos de mediación entre padres/madres e hijos/as, se toman como punto de partida algunos elementos planteados por el psicólogo norteamericano Carl Rogers, iniciador del enfoque centrado en la persona y el pedagogo brasileño Paulo Freire. Ninguno de los dos desarrolla de manera específica las relaciones dentro del seno familiar, pues el primero parte de la relación necesaria en el proceso de psicoterapia -mismo que después adapta a los ámbitos educativo y comunitario/social-y el segundo genera la mayoría de sus postulados en lo que se ha llamado la educación popular o liberadora, situada principalmente en el ámbito comunitario. Sin embargo, se encuentra en sus planteamientos un recurso importante para la comprensión del tipo de relación necesaria para que entre padres e hijos se construyan acuerdos de ganar-ganar, tanto como para comprender el tipo de ambiente y relación que el mediador habrá de generar para facilitar la mediación entre ellos cuando sus servicios sean requeridos.

Para Rogers (1978), la relación es el núcleo de la orientación, del proceso tera- péutico o, de manera más general, de cualquier proceso de crecimiento, entre los que se incluye la relación padres-hijos y la relación entre mediador y mediados. "La cualidad del encuentro [...] es el elemento más significativo para determinar su efectividad" (p. 121). Una relación de ayuda depende de que el facilitador, que puede ser terapeuta, maestro, mediador o madre/ padre de familia, desarrolle tres actitudes básicas: congruencia, aceptación y empatía, mismas que solo tienen sentido "en un contexto de gran respeto por la persona y sus potencialidades" (p. 130). Por su parte, Freire (1983), al referirse a la relación entre educador y educando (padre/madre-hijo) en la que se logra un clima de confianza plantea que esta se basa "en el amor, la humildad y la fe en los hombres" (p. 105).

El diálogo o la relación dialógica entre adultos y niños es una forma concreta de que los derechos de los niños a participar, tener opiniones propias y expresarlas, así como a ser escuchados y tomados en cuenta, sean realizados. Para ello se requiere la decisión y la actitud de los adultos, pues para que los niños se sientan en libertad para expresarse, es necesaria la presencia de adultos capaces de escucharles, que intenten en serio "comprender, dar valor a las palabras, a las verdaderas intenciones de quien habla. Todos los niños hablan, pero no siempre los adultos son capaces de recoger el mensaje” (Tonucci, 2003, p. 21). 
Un proceso de comunicación profunda, de diálogo verdadero entre padres e hijos, exige congruencia de parte de los mayores. "Un padre eficiente se permite a sí mismo ser una persona, una persona real. Los niños aprecian profundamente esta cualidad de autenticidad y de humanidad de sus padres" (Gordon, 1977, p. 24). Favorecer una educación de los hijos centrada en ellos, requiere además de una aceptación incondicional, una escucha activa y una comprensión empática de la experiencia del niño/a.

La relación dialógica implica una relación de poder en la que la autoridad se fortalece con el ejemplo y se basa en el reconocimiento y la confianza mutuos y no en la imposición autoritaria de la visión de uno sobre otro. Este es uno de los principales retos en la resolución pacífica de conflictos entre adultos y niños, pues la cultura dominante hasta nuestros días sigue repitiendo y reproduciendo relaciones autoritarias y dando legitimidad a la violencia como "correctivo".

Fluir en ese encuentro, significa dejarnos dominar por el amor, el respeto, la comprensión, el agradecimiento, la compasión y el interés por los demás y no por actitudes egoístas centradas en uno mismo, motivadas por la codicia, el odio, los prejuicios, la desconfianza y la agresividad que habitualmente dominan nuestros pensamientos. La gente suele decir: "este mundo es cruel y para sobrevivir también hay que ser cruel". Con humildad, disiento de este punto de vista (Gandhi, 2015, p. 15).

El tipo de relación que se plantea exige adoptar un estilo de comunicación no violenta, lo que representa un paso fundamental para cambiar la forma en que se establece la comunicación y se abordan los conflictos, Gandhi define este como el primer paso para "crear un mundo donde impere la compasión” (2015, p. 15).

Aunque en términos generales la empatía se ha definido como la capacidad de comprender la experiencia del otro sin perder la propia condición o perspectiva (Papadimitriou y Romo, 2005), lo que coloquialmente se ha definido como "ponerse en los zapatos del otro", es relevante incorporar algunos elementos más sobre la empatía, que se ha definido como una actitud (Rogers, 1978b) y como una competencia (Papadimitriou y Romo, 2005). La empatía es una actitud que requiere a la totalidad de la persona y "se transmite con todo el cuerpo"; que "supone mucho más que incorporar información con los oídos. Quienes escuchan con empatía usan sus ojos para detectar una prueba física de las emociones, utilizan la imaginación para percibir la situación desde la perspectiva del niño" (Zaritzky, 2011, p. 162). Generar empatía con niñas, niños y adolescentes y conectarse con las emociones que experimentan requiere atender sus expresiones 
corporales y faciales, pues si en cualquier persona adulta, el lenguaje no verbal es importante, en los niños cobra una relevancia mayor.

La escucha activa exige una atención plena tanto al lenguaje verbal como al no verbal y una intención decidida de tratar de comprender la perspectiva del otro. Gordon (1977), quien desarrolló una abundante experiencia y teoría sobre la educación centrada en niñas, niños y adolescentes (en las/os estudiantes en el ámbito escolar y en los hijos/as en la familia), planteó con claridad las implicaciones de la escucha activa según las diferentes edades de desarrollo y fue categórico en la necesidad de escuchar a niñas y niños desde edades muy tempranas. Hace referencia a que escuchar de manera activa a niños de tres o cuatro años hace maravillas, pero se cuestiona sobre cómo podría hacerse en los primeros años: “¿qué podemos hacer con infantes y pequeños que empiezan a dar ya sus primeros pasos y no saben hablar?" (Gordon, 1977, p. 93).

En el caso de niñas y niños más pequeños (primera infancia), el adulto requiere una comprensión precisa del lenguaje no verbal del o la infante, tanto como la capacidad de responder de manera efectiva a dichos mensajes. El citado autor define como equívoca la idea de que niñas y niños muy pequeños no sepan qué necesitan y qué sienten, así como que no tengan la capacidad de generar soluciones a los problemas que enfrentan (Gordon, 1977, p. 93). El reto para el adulto es mayor, pues, además de tener la empatía necesaria para comprender las necesidades del infante, requiere la habilidad de comunicarse de manera efectiva en el canal no verbal.

En talleres con papás y mamás de niños pequeños, trabajando sobre resolución pacífica de conflictos facilitados por la autora, una madre de familia planteó el siguiente problema con su hijo: ella entraba a las 8:30 al trabajo y antes, dejaba a su hijo de dos años en la guardería. Sentía mucha presión porque el niño desayunaba en la estancia infantil. Para que ello ocurriera, tenía que registrar su entrada antes de las 8:00. Si llegaba a las 8:01, tenía que darle de almorzar y dejarlo después, lo que implicaba llegar tarde a su trabajo. Ella se sentía muy estresada porque cuando lo estaba vistiendo, el niño "la hacía enojar"; "parece que lo hace adrede y que se propone que lleguemos tarde". Lo que ocurría era que ella le ponía la playera y él se la quitaba, ella se la volvía a poner y él volvía a sacársela. Después de hacer un ejercicio de empatía, en el que ella "se convirtió" en ese niño de dos años, ella se dio cuenta que el niño lo que quería era jugar. Así, quedaron expuestas las necesidades o intereses de ambos: ella tenía necesidad de llegar puntual su trabajo (y obviamente a la estancia para que el niño desayunara ahí) y el niño tenía necesidad de jugar. A partir de la aclaración de las necesidades 
de ambos, ella pudo generar alternativas en las que ambos vieran satisfechas sus necesidades. Como primera propuesta, se propuso buscar diferentes maneras de motivarlo para que el proceso de vestirse se realizara jugando (él solo o entre ambos).

El pensar que la forma activa de escuchar es solo útil cuando los chicos son lo suficientemente grandes para hablar, constituye una falta de comprensión. El hacer uso de la forma activa de escuchar requiere de un entendimiento adicional de la comunicación no verbal y de la forma en que los padres responden eficazmente a dichos mensajes no verbales transmitidos por sus hijos más pequeños. Más aún, los padres de chicos muy pequeños con frecuencia piensan que solo debido a que estos niños dependen de los adultos en muchas de sus necesidades, tienen muy poca capacidad para llegar a sus propias soluciones para los problemas con los que se enfrentan en la vida. Esto también es falso (Gordon, 1977, p. 93).

Para Gordon es importante comprender que las personas, desde su primera infancia, tienen necesidades, igual que en etapas posteriores de la niñez, la adolescencia y la edad adulta. Por tal motivo, enfrentan también problemas para la satisfacción de dichas necesidades. Entonces, la madre o el padre de niños muy pequeños "debe aprender a escuchar con precisión tanto como el padre de niños mayores. Es una forma diferente de escuchar, primordialmente, porque los infantes se comunican de una forma no verbal" (Gordon, 1977, p. 95). Ser eficaces, en el sentido de lograr un tipo de relación entre madre/padre e hijo y de encontrar formas de resolución de los conflictos (necesidades que se contraponen) pacíficas y en perspectiva de ganar-ganar, "depende en gran medida de la precisión de la comunicación entre el padre y el niño" (Gordon, 1977, p. 96).

Hendricks (2001) concluye en sus investigaciones, que "los niños de todas las edades cuentan con la capacidad para expresar sus pensamientos con mucha claridad y con una gran sensibilidad" (p. 286). Esa debería ser razón suficiente para que los adultos -incluidas las instituciones- hicieran un esfuerzo serio por escucharles. En definitiva, "la mejor manera de entender las experiencias de los niños consiste en proporcionarles las oportunidades para expresarse por sí mismos (con sus propias palabras) y escuchar lo que tienen que decir" (Jamison y Gilbert, 2001, p. 298). Si se trata entonces, de favorecer la resolución noviolenta de conflictos entre padres e hijos, es menester, a fin de comprender cuáles son sus necesidades, sentimientos, experiencias y opiniones, abrir los espacios para escucharles y hacerlo de una manera activa. Para lograrlo, será necesario entonces, "que el oyente tenga las habilidades para entender lo que el niño está 
comunicando" (Tapp y Henaghan, 2001, p. 171). En palabras de Atwool (2001), para que un niño sea escuchado, "debemos estar preparados para oírlo” (p. 127). Según ella, existen numerosas pruebas de que en términos generales los adultos no son buenos para hacerlo, por lo que es un área en la que se necesita generar conciencia y trabajar mucho.

Faber y Mazlish (1980) desarrollaron un manual de comunicación entre padres e hijos al que titularon Cómo hablar para que los niños escuchen y cómo escuchar para que los niños hablen. En los objetivos planteados se encuentra una definición clara del tipo de comunicación y escucha que tratan de promoverse para la resolución pacífica de los conflictos, incluyendo la mediación: se busca encontrar la manera de vivir con la que podamos sentirnos satisfechos y favorecer que quienes son importantes para nosotros se sientan satisfechos de sí mismos; de vivir libres de culpas y recriminaciones; de expresar el coraje sin dañar a otros; de reconocer y respetar las necesidades de los hijos y también reconocer y respetar las nuestras; y de lograr que nuestros hijos sean responsables y acomedidos. $\mathrm{Si}$ pudiera concentrarse todo ello en un objetivo general, sería el de "dejarles a nuestros hijos un legado diferente, una forma de comunicación que puedan usar durante el resto de sus vidas con sus amigos, sus compañeros de trabajo, sus padres, sus cónyu- ges y algún día con sus propios hijos" (Faber y Mazlish, 1980, p. 178).

Si los objetivos planteados se logran en la relación entre padres e hijos, sin duda estarán siendo capaces de resolver sus conflictos de manera pacífica, a través de la generación de soluciones que satisfagan las necesidades de ambos. Si los padres no están siendo capaces de facilitar procesos comunicativos de esta índole, la intervención de un tercero (facilitador o mediador) habrá de plantearse la creación de un ambiente propicio para desarrollarlos, a través de las actitudes básicas descritas arriba.

Lograr dichos objetivos hace imperativo escuchar a los niños. De acuerdo con Tonucci, "a los niños hay que dejarlos hablar, primero, porque lo merecen [...]. Pero, además, porque su palabra es valiosa” (Alonso, 2017, párrafo 5). En general, niñas y niños tienen una perspectiva incluyente y piensan en alternativas que son buenas para todos, que incluyen las necesidades propias y las de los otros. Esto ocurre porque los niños, al no estar invadidos por los vicios y las dinámicas en las que están sumergidos los adultos (prisas, intereses privados, competencia), "tienen una mayor libertad de pensamiento y pueden hacer propuestas más abiertas” (Alonso, 2017, párrafo 17).

En el caso de los conflictos familiares, escuchar a los niños es fundamental para lograr una comprensión más completa de la situación o el problema. Smith y Taylor (2001a) reconocen la importancia de escu- 
charles y tomar en cuenta sus opiniones, pues comprender la realidad de las familias solo desde la mirada de los adultos (padres o expertos), ofrece solo una parte de la realidad. La perspectiva de niñas, niños y adolescentes es fundamental para entenderles a ellos mismos, para entender sus necesidades, intereses y sentimientos y, con ello, para tener una comprensión más clara del conflicto con los padres. "La percepción que los niños tienen de su vida y sus experiencias puede ser una gran aportación para crear mejores condiciones para la niñez en el futuro" -y también en el presente- (Smith y Taylor, 2001a, p. 21). Además, "otorgar a los niños la dignidad y el respeto de saber lo que opinan y proporcionarles las oportunidades de información, explicaciones y retroalimentación significa reconocer que la justicia procedimental es importante para los niños" (Smith y Taylor, 2001b, p. 50). Esto genera una mejor disposición para aceptar las decisiones que se toman en asuntos que les afectan y para asumir responsabilidades.

Gordon (1977) reconoce la importancia de escuchar a los niños para que ellos mismos generen la solución de sus problemas y formen parte de la solución de los conflictos que les involucran tanto a ellos como a su madre o padre, para lo que la escucha activa es el ingrediente fundamental.

Escuchar a niñas, niños y adolescentes exige reconocer la necesidad de su aporte. Saber, como ocurre con el resto de los con- flictos, que, si son parte del problema, son también parte de la solución. En palabras de Tonucci (2003):

Escuchar significa tener necesidad de la contribución del otro. No basta con estar interesados, motivados, convencidos de que es una buena técnica para implicar a los niños hay que sentir sincera y urgentemente su necesidad. Lo importante es necesitar a los niños. Esta es la primera y verdadera condición para que se pueda dar la palabra a los niños: reconocerlos capaces de darnos opiniones, ideas y propuestas útiles para nosotros, los adultos; capaces de ayudarnos a resolver nuestros problemas. Si esto llega a producirse, la relación con ellos será correcta, entre ciudadanos adultos y ciudadanos niños, pero ciudadanos ahora. Si no, podremos hacer regalos a los niños, pasar con ellos momentos simpáticos y divertidos (especialmente para nosotros), pero seguirán estando excluidos de sus derechos, porque seguirán siendo "futuros ciudadanos" o, si se prefiere, “menores" (p. 22).

Asumir el planteamiento de Tonucci es, entonces, reconocer a niñas, niños y adolescentes como sujetos de derechos, establecer con ellas y ellos una relación de ciudadana a ciudadano, aceptar que, si son parte del conflicto tienen que ser también parte de la solución; es aceptar necesitar- 
les para generar alternativas de solución libres de violencia, que recuperen su voz y sus necesidades valorándolas como igualmente importantes que las del adulto. Implica construir relaciones de cooperación, en las que ambas partes (adulto-niña) quedan satisfechos con la solución. Como se ha expuesto arriba, esto no implica que la persona adulta renuncia a su autoridad, sino que se compromete en buscar formas noviolentas para resolver los conflictos; opta por la búsqueda de soluciones negociadas; se interesa realmente por la experiencia, opiniones y sentimientos del niño o la adolescente; proporciona toda la información necesaria para que la persona menor de edad pueda participar en la toma de decisiones con conocimiento de las consecuencias de todas las opciones y asumiendo la responsabilidad sobre la decisión que tome. Se promueve así un poder cooperativo, en el que cada parte asume la responsabilidad según su nivel de desarrollo y el lugar que ocupa en la relación.

\section{Conclusiones}

Con lo hasta aquí expuesto, se puede plantear, a modo de conclusión general, que la mediación familiar y la participación de niñas, niños y adolescentes en sus procesos constituye un mecanismo que facilita la realización y garantía de derechos, tanto de las personas adultas como de las menores de edad.
Sobre los derechos de la niñez, se pueden desglosar, las siguientes conclusiones parciales:

1. La Convención sobre los Derechos del Niño, la Constitución de los Estados Unidos Mexicanos y la Ley General de los Derechos de Niñas, Niños y Adolescentes representan un marco jurídico y cultural propicio para la participación de niñas, niños y adolescentes en los procesos de mediación.

2. Aunque las publicaciones revisadas se centran mayoritariamente en casos de separación o divorcio, se reconoce la importancia de incorporar la participación infantil en la mediación intergeneracional y de legitimar a niñas, niños y adolescentes como interlocutores válidos, titulares de derechos.

3. El reconocimiento de niñas, niños y adolescentes como sujetos, con derecho a participar, a tener una opinión propia, a ser escuchados y tomados en cuenta en aquellos asuntos que les afectan y/o son de su interés, constituyen una exigencia para que los adultos les escuchen y les tomen en cuenta en la familia, pero también en los ámbitos escolar, comunitario e institucional.

4. La perspectiva de la Convención y de la Ley General plantea un cambio cultural que lleva a una nueva relación de poder entre los adultos y los niños, que exige salir del adultocentrismo y el autori- 
tarismo con que históricamente se ha tratado a niñas, niños y adolescentes, para generar relaciones de poder basadas en el diálogo y en el reconocimiento mutuo, sin negar ni dejar de asumir que el adulto tiene un rol de autoridad.

5. La mediación es un espacio de encuentro y realización de los derechos de niñas, niños y adolescentes. Según Valdebenito (2013), la mediación crea un espacio democrático para la familia, en el que los niños desde pequeños pueden expresarse con libertad y "desenvolverse en un ambiente de tolerancia, comprensión, respeto y solidaridad" que potencia la capacidad de tomar decisiones en temas que son de su interés (p. 58).

6. La mediación representa un mecanismo idóneo que "favorece la autonomía de la voluntad y la autorregulación de los individuos hacia sus propios intereses, dentro de los límites establecidos por el Estado y la norma del Derecho" (Valdebenito, 2013, p. 59). La participación de los niños y ser escuchados por los adultos favorece que sus intereses, necesidades y deseos sean integrados a la discusión y a la generación de acuerdos con los padres.

7. La mediación familiar constituye un mecanismo alternativo para resolver los conflictos y posee el mismo rango constitucional que un litigio ventilado ante los tribunales locales y federales.
Aplicar esta disposición constitucional a la resolución de conflictos en los que están implicadas personas menores de dieciocho años abre posibilidades de acceso a la justicia y de participación en la vida democrática.

8. Analizar, mediar y/o negociar conflictos entre madres/padres e hijos/as implica el reconocimiento mutuo como actores del mismo y la aceptación del otro como interlocutor válido. Así mismo, favorece que niñas, niños y adolescentes participen en la generación de opciones y se responsabilicen de manera cooperativa con sus padres de llevarlas a cabo.

9. Finalmente, es importante señalar que hay literatura en otras disciplinas, como la psicología humanista o la capacitación de madres y padres para la educación de sus hijos que aportan recursos importantes para la mediación familiar, especialmente en la generación de una relación dialógica y en el desarrollo de actitudes de empatía, escucha activa y comunicación efectiva. Retomar estos aportes e incorporarlos en la práctica y la teoría de la mediación es un reto importante.

\section{Fuentes consultadas}

Adorna, C. (1999). Prólogo, en: Fondo de las Naciones Unidas para la Infancia (1998). La participación de los niños y adolescentes en el contexto de la Convención sobre los derechos del 
niño: visiones y perspectivas. Florencia: Unicef-International Child Development Centre (1999), pp. 7-8. Recuperado de: https://www. unicef-irc.org/publications/pdf/bogota.pdf; consulta: 12 de septiembre de 2020.

Alarcón Cañuta, M (2015). Conveniencia de la participación de los niños en el proceso de mediación; en Ars boni et aequi 11(2), pp. 11-47. Recuperado de http://www.arsboni. ubo.cl/index.php/arsbonietaequi/article/ view/13; consulta: 18 de septiembre de 2020. Almada Mireles, M. L. (2012). Las familias en Ciudad Juárez; en Barraza Limón, L. y Almada Mireles, $\mathrm{H}$., La realidad social y las violencias. Ciudad Juárez. Universidad Autónoma de Ciudad Juárez / Incide Social, A. C.

Alonso, S. (2017). Francesco Tonucci: "A los niños se les niega ahora su autonomía para jugar", en Levante. El Mercantil Valenciano, 24 de abril. España. Recuperado de: https://www. levante-emv.com/sociedad/2017/04/24/ francesco-tonucci-ninos-les-niega/1557972. html; consulta: 12 de septiembre de 2020.

Arellano, J. (2017). Editorial: Los mecanismos alternativos al proceso judicial; en Centro de Estudios de Justicia de las Américas, Sistemas Judiciales. Una perspectiva integral sobre la administración de justicia. CEJA, 16(20), pp. 4-5. https://inecip.org/wp-content/uploads/ Sistemas-20-web-14-marzo-2017.pdf; consulta: 16 de septiembre de 2020.

Asociación Matiz, Educación en Valores (2015). Resolución pacífica de conflictos. Guía de recursos y experiencias prácticas para educadores/as. País Vasco: Ayuntamiento de
Vitoria-Gasteiz. Recuperado de https://www. ucm.es/data/cont/media/www/pag-50196/ documentos/Gu\%C3\%ADa\%20duIN.pdf; consulta: 19 de septiembre de 2020.

Astelarra, J., (2007). “Género y cohesión social: Una primera aproximación”, en Astelarra, J. (coord.), Género y cohesión social, Fundación Carolina, CeALCI, pp. 3-12.

Atwool, N. (2001). Niños expuestos a riesgos y traumas. En Smith, A. B., Taylor, N. J. y Gollop, M. M. (coords.). Escuchemos a los niños. México: Fondo de Cultura Económica, pp. 113-136.

Carbonel, M. (2006). Familia, constitución y derechos fundamentales; en Álvarez de Lara, R.M. (coord.), Panorama internacional de derecho de familia. Culturas y sistemas jurídicos comparados. México: IIJ-UNAM, pp. 81-95. Recuperado de: https://archivos.juridicas.unam.mx/www/bjv/libros/5/2287/7. pdf; consulta: 19 de septiembre de 2020.

Cascón, P. (2004). Educar en y para el conflicto. Cátedra Unesco sobre Paz y Derechos Humanos de la Universitat Autonoma de Barcelona. Recuperado de: http://pacoc.pangea. org/documentos/educarenyparaelconflicto. pdf; consulta: 12 de septiembre de 2020.

Cillero, M. (1999). Infancia, Autonomía y Derechos: Una cuestión de principios. Recuperado de: http://www.iin.oea.org/Cursos_a_ distancia/explotacion_sexual/Lectura4. Infancia.DD.pdf; consulta: 12 de septiembre de 2020.

Cobb, S. (1997). The Domestication of Violence in Mediation; en Law er Society Review, (31)3, 
pp.397-449. DOI:10.2307/3054041. Recuperado de https://www.jstor.org/stable/3054041; consulta: 18 de septiembre de 2020.

Comisión Nacional de los Derechos Humanos (2018). Las familias y su protección jurídica. México: CNDH. Recuperado de: https:// www.cndh.org.mx/sites/default/files/doc/ Programas/Ninez_familia/Material/trip-familias-juridicas.pdf; consulta: 17 de septiembre de 2020.

Faber, A. y Mazlish, E. (1980). Cómo hablar para que los niños escuchen y cómo escuchar para que los niños hablen. México: Planeta.

Fondo de las Naciones Unidas para la Infancia (2013). Superando el adultocentrismo. Santiago de Chile: Unicef. Recuperado de https://www.yumpu.com/es/document/ $\mathrm{read} / 36645660 /$ superando-el-adultocentrismo-4, consulta: 12 de septiembre de 2020.

Fondo de las Naciones Unidas para la Infancia (2017). Una situación habitual. Violencia en las vidas de los niños y adolescentes. Datos fundamentales. Nueva York: Unicef. Recuperado de https://www.unicef.org/publications/files/Violence_in_the_lives_of_children_Key_findings_Sp.pdf; consulta: 19 de septiembre de 2020.

Fondo de las Naciones Unidas para la Infancia (s/f). Hablemos de participación infantil. Recuperado de: https://ciudadesamigas.org/hablemos-de-participacion-infantil/; consulta: 12 de septiembre de 2020.

Freire, P. (1983). Pedagogía del oprimido. México: Siglo XXI.
Gandhi, A. (2015). Prefacio. En Rosenberg, M. (2015). Comunicación no violenta. Un lenguaje de vida. Buenos Aires: Gran Aldea Editores.

García, L. y Bolaños, I. (2010). La familia dialoga y llega acuerdos: la mediación familiar. Madrid: Dirección General de Familia de la Comunidad de Madrid, pp. 52-63. Recuperado de: https://www.ucm.es/data/cont/media/www/pag-41339/lafamiliadialogayllegaaacuerdos.pdf; consulta: 12 de septiembre de 2020.

Giddens, A. (1998). Sociología. Madrid: Alianza Editorial.

Gigena, C. (2017). Los mecanismos alternativos al proceso judicial en la región y su aporte al acceso a la justicia. Entrevistas realizadas por Constanza Gigena, abogada investigadora de CEJA, Sistemas Judiciales. Una perspectiva integral sobre la administración de justicia. CEJA, 16(20), pp. 125-134. https://inecip.org/ wp-content/uploads/Sistemas-20-web-14marzo-2017.pdf; consulta: 16 de septiembre de 2020.

Girard, K. y Koch, S.J. (1997). Resolución de conflictos en las escuelas. Manual para educadores. Argentina: Ediciones Granica, S. A.

Gollop, M. (2001). Entrevistar a los niños: una perspectiva de investigación. En Smith, A., Taylor, N. y Gollop, M. (coords.). Escuchemos a los niños. México: Fondo de Cultura Económica, pp. 56-85.

Gordon, T. (1977). P.E.T. Padres Eficaz y Técnicamente preparados, México: Diana.

Hendricks, A. K. (2001). Papás buenos y papás malos, papás divertidos y papás tristes: la 
opinión de los niños sobre el padre. En Smith, A., Taylor, N. y Gollop, M. (coords.). Escuchemos a los niños. México: Fondo de Cultura Económica, pp. 257-294.

Hernández-Tirado, H. (2016). Mediación y justicia. Hacia una tutela extrajudicial efectiva. Universidad de Sonora.

Jamison, A. y Gilbert, L. (2001). La opinión de los niños en la comunidad y el gobierno. En Smith, A., Taylor, N. y Gollop, M. (coords.). Escuchemos a los niños. México: Fondo de Cultura Económica, pp. 295-330.

Lay-Lisboa, S. y Montañés, M. (2018). De la participación adultocéntrica a la disidente: La otra participación infantil, en Psicoperspectivas, 17(2). Valparaíso: Pontificia Universidad Católica. Recuperado de: http://www.psicoperspectivas.cl/index.php/psicoperspectivas/article/viewFile/1176/869; consulta: 12 de septiembre de 2020.

Martínez de Munguía, B. (1999). Mediación y resolución de conflictos. Una guía introductoria. México: Editorial Paidós Mexicana.

Moore, C. (2006). El proceso de mediación. Métodos prácticos para la resolución de conflictos. Buenos Aires: Granica.

Mirabal, D. (2003, enero-diciembre). Técnicas para manejo de conflictos, negociación y articulación de alianzas efectivas. Provincia, 10, pp. 53-71. Universidad de los Andes Mérida, Venezuela. Recuperado de: https://www. redalyc.org/pdf/555/55501005.pdf; consulta: 12 de septiembre de 2020.

Morlachetti, A. (2014). La Convención sobre los derechos del niño y la protección de la infancia en la normativa internacional de derechos humanos, en Beltrão, J., Monteiro de Brito, J., Gómez, I., Pajares, E., Paredes, F. y Zúñiga, Y. (coords.). Derechos humanos de los grupos vulnerables. Manual. Barcelona: Red de Derechos Humanos y Educación Superior, pp. 19-72. Recuperado de: https://www. upf.edu/dhes-alfa/materiales/res/dhgv_pdf/ DHGV_Manual.21-42.pdf

Munuera Gómez, M. y Blanco Larrieux, M. (2011). Una mirada hacia mediar o no mediar en casos de violencia: Sara Cobb; en Revista de Mediación, 4(7), pp. 32-37. Recuperado de: https://revistademediacion.com/ wp-content/uploads/2013/10/Revista-Mediacion-7-04.pdf; consulta: 19 de septiembre de 2020.

Papadimitriou, G. y Romo, S. (2005). Capacidades y competencias para la resolución noviolenta de conflictos. México: Mc-Graw Hill Interamericana.

Parkinson, L. (2005). Mediación familiar. Teoría y práctica: Principios y estrategias operativas. Barcelona: Gedisa.

Parra, L. (2014). Manual para la formación y capacitación en mediación comunitaria. México: Centro de Seguridad Urbana y Prevención SC.

Pérez, J. (1999). El niño como sujeto social de derechos: Una visión del niño para leer la Convención. En: Fondo de las Naciones Unidas para la Infancia (1998). La participación de los niños y adolescentes en el contexto de la Convención sobre los derechos del niño: visiones y perspectivas. Florencia: Unicef-Internatio- 
nal Child Development Centre (1999), pp. 4546. Recuperado de: https://www.unicef-irc. org/publications/pdf/bogota.pdf; consulta: 12 de septiembre de 2020.

Pérez Contreras, M. (2013). Violencia y maltrato infantil en la familia: Una reflexión actual y prospectiva; en Publicación Electrónica, núm. 8, Investigaciones Jurídicas. UNAM. Recuperado de: https://archivos.juridicas. unam.mx/www/bjv/libros/8/3582/3.pdf; consulta: 18 de septiembre de 2020.

Plitt, V. y Cadavid, J. (2011). La conciliación como cultura ciudadana; en Ospina, $\mathrm{H}$., Alvarado, S. y López, L. (comps.) (2011). Educación para la paz. Una pedagogía para consolidar la democracia social y participativa. Bogotá: Cooperativa Editorial Magisterio, pp. 233-240.

Ripoll-Millet, A. (2000). Mediación familiar. Barcelona: Paidós. Recuperado de: https://www.avntf-evntf.com/wp-content/ uploads/2016/06/Mediaci\%C3\%B3n-Familiar.-\%C3\%81lex-Ripoll-Millet.pdf; consulta: 12 de septiembre de 2020.

Rogers, C. (1978a). La relación interpersonal: el núcleo de la orientación. En Lafarga, J., y Gómez del Campo, J. (Eds.). Desarrollo del Potencial Humano: Aportaciones de una psicología humanista, 2. (pp.121-136). México, Distrito Federal: Trillas.

Rogers, C. (1978b). Condiciones necesarias y suficientes del cambio terapéutico de personalidad. En Lafarga, J., y Gómez del Campo, J. (Eds.). Desarrollo del Potencial Humano: Apor- taciones de una psicología humanista, 1. México, Distrito Federal: Trillas, pp. 77-92.

Romero, F. (2002). La mediación familiar. Un ejemplo de aplicación práctica: la comunicación a los hijos de la separación de los padres. El papel del mediador. En Revista del Ministerio del Trabajo y Asuntos Sociales, 40, pp. 31-54. Universidad de la Rioja, España. Recuperado de: https://dialnet.unirioja.es/ servlet/articulo?codigo=296385; consulta: 12 de septiembre de 2020.

Romero, J. (2016). El papel que ocupan los menores en la mediación familiar. Trabajo para obtener el grado como Máster en Mediación y Resolución Extrajudicial de Conflictos de la Facultad de Ciencias Sociales, Jurídicas y de la Comunicación de la Universidad de Valladolid Segovia, España, pp. 41-75. Recuperado de: https://uvadoc.uva.es/bitstream/10324/18255/1/TFM-N.34.pdf; consulta: 12 de septiembre de 2020.

Romero, J. (2019). Mediación familiar intergeneracional. Cuando el amor incondicional no es suficiente. Granada, España: Instituto Europeo de Estudios Empresariales. Revista digital. Recuperado de: https://revistadigital. inesem.es/juridico/mediacion-familiar-intergeneracional/; consulta: 12 de septiembre de 2020.

Silva, F. y Martínez, G. (2019). La justicia alternativa como derecho humano. Jurídicas CUC, 15(1), pp. 263-284. DOI: http://dx.doi. org/10.17981/juridcuc.15.1.2019.10; consulta: 15 de septiembre de 2020. 
Smith, A. y Taylor, N. (2001). Introducción. En Smith, A., Taylor, N. y Gollop, M. (coords.). Escuchemos a los niños. México: Fondo de Cultura Económica, pp. 21-28.

Smith, A. y Taylor, N. (2001b). El contexto sociocultural de la infancia: el equilibrio entre dependencia y autonomía. En Smith, A., Taylor, N. y Gollop, M. (coords.). Escuchemos a los niños. México: Fondo de Cultura Económica, pp. 29-55.

Suares, M. (2008). Mediación. Conducción de disputas, comunicación y técnicas. Buenos Aires: Paidós.

Suares, M. (2015). Mediando en conflictos familiares. Buenos Aires: Paidós.

Tapp, P. y Henaghan, M. (2001). Derecho familiar: concepciones sobre la infancia y opiniones de los niños. Las implicaciones del artículo 12 de la Convención de las Naciones Unidas sobre los Derechos del Niño. En Smith, A., Taylor, N. y Gollop, M. (coords.). Escuchemos a los niños. México: Fondo de Cultura Económica, pp. 164-193.

Tonucci, F. (2003). Cuando los niños dicen: ¡Basta! Buenos Aires: Editorial Losada.

Valdebenito, C. (2013). Presencia de los niños y niñas en la Mediación Familiar en Chile. En RumboTs, VII(7), Santiago: Universidad Central de Chile, pp. 48-69. Recuperado de http://revistafacso.ucentral.cl/index.php/ rumbos/article/view/138/134; consulta: 12 de septiembre de 2020.

Valero Matas, J. A. (2010). La inclusión de los niños en el proceso de mediación familiar. Reflexiones desde el caso neozelandés. Revista de investigaciones políticas y sociológicas, 9(1), pp. 89-100. https://minerva.usc.es/xmlui/ bitstream/handle/10347/8390/pg_091-102_ rips9-1.pdf?sequence=1\&isAllowed=y; consulta: 12 de septiembre de 2020.

Zaritzky, G. (2011). La formación para la convivencia y los derechos del niño; en Ospina, H., Alvarado, S. y López, L. (comps.). Educación para la paz. Una pedagogía para consolidar la democracia social y participativa. Bogotá: Cooperativa Editorial Magisterio, pp. 69-154.

\section{Leyes $y$ tratados}

Comité de los Derechos del Niño de la Organización de las Naciones Unidas (2009). Observación Núm. 12. El derecho del niño a ser escuchado. Ginebra. Recuperado de: https:// www.acnur.org/fileadmin/Documentos/ BDL/2011/7532.pdf; consulta: 12 de septiembre de 2020.

Constitución Política de los Estados Unidos Mexicanos. 5 de febrero de 1917. Última reforma DOF 08/05/2020. http://www.diputados.gob.mx/LeyesBiblio/pdf_mov/Constitucion_Politica.pdf; consulta: 12 de septiembre de 2020.

Ley General de Acceso de las Mujeres a una Vida Libre de Violencia. 1 de febrero de 2007. Recuperado de: http://www.dof.gob. $\mathrm{mx} /$ nota_detalle.php?codigo $=4961209 \& \mathrm{fe}-$ cha=01/02/2007; consulta: 19 de septiembre de 2020.

Ley General de los Derechos de Niñas, Niños y Adolescentes. Diario Oficial de la Federación, 4 de diciembre de 2014. Última refor- 
ma DOF 17/10/2019. http://www.diputados. gob.mx/LeyesBiblio/pdf/LGDNNA_171019. pdf; consulta: 12 de septiembre de 2020.

Ley de Justicia Alternativa del Estado de Chihuahua Ley. Periódico Oficial del Estado 43, 30 de mayo de 2015. Última reforma 12/09/2018. Núm. 73. http://www.congresochihuahua2.gob.mx/biblioteca/leyes/archivosLeyes/1164.pdf; consulta: 12 de septiembre de 2020.

Organización de las Naciones Unidas (1990). Convención sobre los Derechos del Niño. Recuperado de: https://www.ohchr.org/sp/ professionalinterest/pages/crc.aspx; consulta: 12 de septiembre de 2020. 